\title{
Associations between park features and adolescent park use for physical activity
}

\author{
Nicole Edwards ${ }^{1,3^{*}}$, Paula Hooper ${ }^{1}$, Matthew Knuiman ${ }^{3}$, Sarah Foster ${ }^{1}$ and Billie Giles-Corti ${ }^{2}$
}

\begin{abstract}
Background: Eighty per cent of adolescents globally do insufficient physical activity. Parks are a popular place for adolescents to be active. However, little is known about which park features are associated with higher levels of park use by adolescents.

Objectives: This study aimed to examine which environmental park features, and combination of features, were correlated with higher levels of park use for physical activity among adolescents. By examining park features in parks used by adolescents for physical activity, this study also aimed to create a park 'attractiveness' score predictive of adolescent park use, and to identify factors that might predict use of their closest park.
\end{abstract}

Methods: Adolescents $(n=1304)$ living in Geraldton, a large rural centre of Western Australia, completed a survey that measured physical activity behaviour, perceptions of park availability and the main park used for physical activity. All parks in the study area $(n=58)$ were digitized using a Geographic Information System (GIS) and features audited using the Public Open Space Desktop Auditing Tool (POSDAT).

Results: Only $27 \%$ of participants reported using their closest park for physical activity. Park use was associated with seven features: presence of a skate park, walking paths, barbeques, picnic table, public access toilets, lighting around courts and equipment and number of trees $>25$. When combined to create an overall attractiveness score, every additional 'attractive' feature present, resulted in a park being nearly three times more likely to be in the high use category.

Conclusions: To increase park use for physical activity, urban planners and designers should incorporate park features attractive to adolescents.

Keywords: Adolescents, Built environment, GIS, Park quality, Parks, Physical activity

\section{Introduction}

The health benefits of physical activity for children and adolescents are substantial, yet $80 \%$ of adolescents worldwide do not achieve the recommended 60 minutes of daily moderate to vigorous physical activity [1]. One way to increase activity levels among adolescents, is to understand the relationship between physical activity and the environments they use for physical activity. One environment where physical activity often occurs is neighbourhood parks. Research shows a greater availability of parks and

\footnotetext{
* Correspondence: nicole.edwards@uwa.edu.au

'Centre for the Built Environment and Health, School of Sport Science, Exercise and Health and School of Earth and Environment, University of Western Australia, 55 Broadway, Nedlands 6009, WA, Australia

${ }^{3}$ School of Population Health, University of Western Australia, 55 Broadway, Nedlands 6009, Perth, Western Australia

Full list of author information is available at the end of the article
}

recreational facilities is positively associated with levels of adolescents' physical activity [2-5] however, the evidence for park and neighbourhood attributes independently encouraging physical activity among adolescents is limited and results have been mixed [6].

Much is known about what features attract adults to use parks, however less is known about which features attract adolescents to use particular parks. Park features and surrounding environments are typically examined for associations with outcomes such as physical activity levels and weight status [5,7-11]. To date, a range of environmental features have been found to be associated with adolescent park use such as: availability; proximity [12-14]; park size [15]; adolescents' perceptions of the environment [16]; quality; and use by friends [16]. 
Other studies have examined the specific park attributes associated with adolescent health behaviours and outcomes. For example, Potwarka et al. found healthy weight status among children (2-17 years) was associated with proximity to specific park features such as the availability of a park playground [10]. By contrast, in a study of 13-15 year olds, Timperio et al. (2008) found the presence of playgrounds within $800 \mathrm{~m}$ of participant's homes was not associated with physical activity [17], possibly because playgrounds were for younger children. Other park attributes associated with higher levels of park use or physical activity among youth, include the presence of: picnic areas; water features [15]; playing fields; [18] basketball courts [15,19]; and again, playgrounds $[5,18]$.

Exposure to greener neighbourhoods and spaces has been associated with lower BMI among children and youth (3-16 years) [20] and higher levels of MVPA among children 8-14 years [21]. However, whether the 'greenness' of a park could potentially influence adolescent park use appears not to have been explored to date.

Evidence suggesting that specific park features may influence youth physical activity [22], combined with the inconsistencies in evidence to date, highlights the need for research to better understand the features of parks that attract young people. In addition to individual park features, it is plausible that a combination of park features might be important when designing parks that appeal to adolescent users. For instance, park attractiveness scores have been developed in previous studies of adults, and were found to be associated with higher levels of walking $[23,24]$. However, given the differences between adults and adolescents in terms of specific park features associated with park use [22] an adolescent-specific park attractiveness score is needed to better understand features of park use that drive adolescent park use.

To understand adolescent park use, parks need to be audited for their features and quality. Traditionally, park features have been captured using audit tools, such as EAPRS [25], POST, CPAT [26,27] and C-POST [28] that require site visits to the park by auditors. More recently, remote sensing [29] and geographic information systems (GIS) techniques have been applied to generate objective measures of park features [30].

Using remote sensing and GIS allows data traditionally captured by on-the-ground audits to be collected remotely. Furthermore, it enables measurement of park features previously not captured in audit tools such as: a measure of park 'greenness' using Normalized Difference Vegetation Index (NDVI); the number and size of tree canopies within or around the park; the orientation of surrounding houses; and categorization of surrounding roads. Studies that use GIS to assess the influence of environmental features, such as parks, on physical activity typically measure distances between participant's residence and their nearest parks or generate park service areas around parks to represent recreation [2,10,11,31-34]. This method assumes people use their closest park however in reality people may choose to travel to use a more attractive park.

The aim of this current study was to examine which environmental park features, and combination of features, correlated with higher levels of park use for physical activity by adolescents. By examining park features in those parks reported as being used by adolescents, this study also aimed to create an attractiveness score that is predictive of adolescent park use for physical activity and identify factors that might predict use of the closest park to where adolescents live.

\section{Methods}

The study was conducted in Geraldton, a large rural centre with a population of approximately 39,000 people, on the coast of Western Australia. It is located $420 \mathrm{~km}$ north of the capital Perth.

\section{Participant data on parks used}

Cross sectional data of physical activity attitudes and behaviours were collected in 2006 from 12-15 year olds $(n=1304)$ as part of the 'Up4It' study. The data collection methods and demographic details are described elsewhere [8]. In brief, the Up4It study surveyed all 12-15 year old adolescents living in the Geraldton study area in attendance at one of the five high schools $(\mathrm{n}=1626)$. This larger survey achieved a response rate of $92 \%$, however this paper is based on participants for whom a residential address could be spatially geocoded $(n=1304,80 \%)$. Socio-economic status (i.e., values ranked in deciles) was attributed to each participant according to the SocioEconomic Indexes for Areas (SEIFA) index of Relative Socio-Economic Disadvantage [35]. The scores attributed to each participant were based on the census collection district in which they lived.

Additionally, each participant reported if they were Aboriginal or Torres Strait Islander.

Survey items asked participants: 1) whether they 'used any park within the last 12 months for physical activity'; and 2) to identify the park they used most often for physical activity.

The number of participants who reported using each park was used as a measure of park use or popularity for physical activity. These data were then used to create a dependent variable representing 'high' and 'low' use. The top quartile (the 15 parks reported as being used by at least 10 participants) was categorized as 'high use 'and the remainder as 'low use'. The 'low use' category included 28 parks that were not reported as being used by any study participant. 


\section{Park layer/audit and access}

Using high resolution ortho-imagery of Geraldton sourced from Landgate (flown in 2006 to correspond with the year the survey data collection), all parks within in the study area were manually digitized $(n=58)$ and their size (i.e., area) computed in ArcMap (ESRI v10.1). "Parks" were defined as areas of public open space typically designed for, or able to cater for, a range of different leisure or recreational activities - both active and passive. These included landscaped, ornamental and manicured gardens or parks, as well as publicly accessible (i.e. free to use) recreation spaces, playing fields, ovals and sports surfaces, such as skate parks. Playing fields or sports courts and facilities with restricted access to the public or where the public were not permitted except on payment (i.e. sports clubs or leisure centres or fenced off school grounds) were not included. These were identified using aerial imagery and verified from the sport and recreation listings held by the local government.

All 58 parks identified were audited to assess their features using a modified version of the Public Open Space Desktop Auditing Tool POSDAT [30]. POSDAT captures park attributes using a combination of web-based information and remote sensing methods. This audit tool has been shown to be a reliable and valid desktop method for auditing parks [30]. Additional GIS methods were used to capture the location of playgrounds, the number of trees; the area of tree canopy within the park; the greenness of the park; the proportion of the park perimeters surrounded by lots fronting the park and surrounded by adjacent road types, park size, proximity of the park to the beach and the number of participants who live within a $800 \mathrm{~m}$ buffer surrounding the park. Items from POSDAT that have been modified or added to this study are outlined in Table 1. The POSDAT item, number of trees present, was previously shown to be valid but had poor inter-rater reliability when tree counts were placed into four categories [30]. To improve the reliability of this item, the number of categories was reduced from four to two, i.e., more or less than 25 trees.

Imagery used in this study was flown in summer months to provide the most temporally relevant to the Up4IT survey data collected. Greenness was measured using NDVI (Landsat TM remote sensing imagery captured in summer 2006 and fully calibrated). NDVI provides an indication of the presence and condition of green vegetation with values ranging from -1 to 1 . Values of -1 generally represent water, while values of zero correspond to bare surfaces such as rock, sand and roads. Higher values (0.2 to 0.4) represent grassland or bushland.

Mean NDVI values for each park were recoded to tertiles based on distribution of data. NDVI values for parks in this study will be low in general because the imagery is collected during summer. As a result, high values indicate extensive irrigation. Scores in the top third were categorized as high NDVI and scores in the bottom two thirds were categorized as low NDVI.

A pedestrian network was created for all accessibility analyses and is detailed elsewhere [8]. Briefly, the Geraldton street network was edited to include paths and potential shortcuts. Distances between a participant's residence (measured as the closest intersection in order to comply with the University of Western Australia Human Research Ethics Committee requirements) and: 1) their closest park and 2) the park they reported using most often for physical activity, were determined using network analyses along the pedestrian street network.

\section{Development of a park quality attractiveness score for adolescents}

The associations between 'high' and 'low' park use for physical activity and park features were examined. Objectively measured park features were individually assessed using crosstabs for categorical variables (with Fisher's exact test) and ANOVAs for continuous variables. Features not present in the park sample (for example, free tennis courts and wetlands) were excluded from analyses. Features that held stronger associations ( $p$ value $<0.2)$ with high/low park use for physical activity progressed to the next phase of analysis.

Each park feature was then examined separately for its association with high/low use for physical activity by adolescents in a logistic regression model that included adjustment for park size and the number of participants who lived within $800 \mathrm{~m}$ of the park. The seven park features that were significantly and positively associated $(p \leq 0.05)$ with park use for physical activity were used to define an attractiveness score relevant to adolescent park use for each park as the number of these seven features that were present in the park. A second park attractiveness score using the combination of features previously established as relevant for adults [23] was also calculated for each park.

\section{Statistical analyses}

Descriptive statistics are presented as percentages for categorical variables and mean (SD) for quantitative variables.

Our measure of high park use was influenced by the spatial distribution of the parks and the participants. As the spatial distribution of parks and participants was not even, we adjusted for number of participants living within $800 \mathrm{~m}$ of park when ascertaining the association with park attributes. Additionally, we adjusted for park size to assess the association with park attributes independent of size. However, in a sensitivity analysis we found that the results were essentially the same when we did not adjust for park size.

The strength of the association (odds ratio per additional feature) between each park attractiveness score and high/ 
Table 1 Additional POSTDAT items and derived methods

\begin{tabular}{ll}
\hline Additional POSDAT item $\quad$ Method \\
\hline Activities
\end{tabular}

Any activity space present

\section{Environmental quality}

Number of trees present in park (Replaces POSDAT item: Estimate the approximate number of trees present 0, 1-50 or 50-100)

Tree canopy area

The proportion of the park area covered by tree canopy

Path shade

\section{Amenities}

Amenity count

\section{Safety}

Park surrounded by minor roads only Replaces POSDAT item 'Are all roads surrounding the POS minor roads or cul-de-sacs?'

Number of lots surrounding park

Number of lots orientation ratio
A binary variable indicating the presence of any activity space (Yes/No) (from a list of 12 different captured on PSDAT) was computed. Playground equipment was excluded.

All tree canopies within the parks were manually digitised in ArcMap and the number of trees within each park calculated. For the purpose of this study, the number of trees were placed into two categories $<25$ trees or $>25$ trees.

All digitised tree canopies within each park were merged in ArcMap to determine a total tree canopy area for each park.

The total area of tree canopy was calculated as a proportion of total park area $\left(\mathrm{m}^{2}\right)$. Total tree canopy area $\div$ park size.

Original POSDAT categories (no pathshade, very poor, poor, medium, good, very good) were collapsed into two categories: High (medium, good and very good) and low (no shade, poor and very poor).

The number of different amenities present (includes; barbeques, seating, picnic tables, toilets, public art, lighting) were summed to give a total count per park.

Road types were objectively categorised (major or minor) using a classification of major and minor roads according to Western Australian Planning Commission policy and local municipality classification.

All roads were attributed as major or minor. All roads surrounding each park were identified Parks were coded as being surrounded by minor roads only (Yes/No).

All residential lots (cadastre obtained from Landgate, dated 2006) surrounding the parks (i.e within a $25 \mathrm{~m}$ buffer of the park perimeter) were identified and a count of lots surrounding each park computed. [36].

Each of the selected residential lots were inspected and classified according to the orientation of the dwelling on the lot to the park it sports or active recreation spaces
Table 1 Additional POSTDAT items and derived methods (Continued)

Perimeter orientation ratio

surrounded; whether it was orientated towards (i.e. facing/ fronting) or away from (i.e. backing onto) the park. [36]. The number of residential lots facing the park was divided by the total number of residential lots surrounding the park. Higher ratios (towards 1.0) indicated a higher proportion of the bordering houses being orientated towards the park [36].

The lot orientation ratio was further refined to determine the proportion of the park perimeter that was bordered by lots fronting the park. The length of the park perimeter surveilled by facing cadastre was identified. This was divided by the total perimeter of the park [36].

\section{Environmental quality}

Greenness

The presence of greenness in each park was calculated using the Extract Normalized Difference Vegetation Index (NDVI) tool and Landsat TM remote sensing imagery (summer 2006). NDVI provides an indication of the presence and condition of green vegetation with values ranging from -1 to 1 . Values of -1 generally represent water, while values of zero correspond to bare surfaces such as rock, sand and roads. Higher values (0.2 to 0.4 ) represent grassland or bushland. Mean NDVI values for each park were determined.

\section{Additional items}

Park size $\left(\mathrm{m}^{2}\right)$

Using the calculate geometry function in ArcMap the area of each park was determined.

Proximity to beach

Distance calculated between the closest point on park perimeter and closest beach access points manually digitized at sites of beach entry. Distances were calculated using the road/pedestrian network.

No. of participants in $800 \mathrm{~m}$ buffer

Points were generated at $10 \mathrm{~m}$ intervals around each park and a service area generated extending $800 \mathrm{~m}$ from each from each point along the road/pedestrian network . The service area around each of the points was dissolved and the number of participant residential points in the service area was determined.

Giles-Corti adult attractiveness score

The attractiveness score previously used by Giles-Corti et al. (ref) was applied to each park. 
low park use was estimated from a logistic regression model that adjusted for park size and number of participants living within $800 \mathrm{~m}$ of the park.

T-tests were conducted to confirm the difference in the mean attractiveness scores of parks that were reported as being used compared with parks not used at all and the difference between parks with high use and low use.

To explore what variables might predict use of closest park, logistic regression analysis was performed with "closest park is the reported park" as the dependent variable. This analysis was restricted to a sub sample of participants who reported using a park for physical activity $(n=751)$. Independent variables included participant demographic characteristics (age, sex, ethnicity and socio-economic status), attractiveness score of the closest park, distance to closest park and the perception of whether or not there were parks or sporting grounds close to where the participant lived. All data analyses were conducted in SPSS version 19.0.

\section{Results}

\section{Characteristics of study participants and characteristics of} study parks

Demographic characteristics of the study participants $(n=1304)$ and environmental characteristics of the parks audited $(n=58)$ are presented in Table 2. Participants were evenly distributed among school year groups and genders. Thirteen percent of participants identified themselves as Aboriginal or Torres Strait Islander. Seventy eight percent of participants lived within $800 \mathrm{~m}$ of a park.

\begin{tabular}{|c|c|}
\hline $\begin{array}{l}\text { Demographic characteristics of participants } \\
(n=1304)\end{array}$ & Number (\%) \\
\hline School year 8 & $448(34)$ \\
\hline School year 9 & $469(36)$ \\
\hline School year 10 & $387(30)$ \\
\hline Male & $633(49)$ \\
\hline Aboriginal/Torres Strait Islander & $169(13)$ \\
\hline High SES & $618(47.4)$ \\
\hline Proximity to park $\leq 800 \mathrm{~m}$ & $1026(78.7)$ \\
\hline Reported using park Yes & $751(57.6)$ \\
\hline Environmental characteristics of parks $(n=58)$ & Mean (SD) \\
\hline Park size $\mathrm{m}^{2}$ & $16,445(25396)$ \\
\hline Number of participants within $800 \mathrm{~m}$ of park & $38.8(24.7)$ \\
\hline
\end{tabular}

The mean park size was $16,445 \mathrm{~m}^{2}$ and the mean number of participants who lived within an $800 \mathrm{~m}$ service area of a park was 38 .

\section{Development of an attractiveness score for park features associated with high park use}

Associations between park attributes and high/low park use are reported in Table 3 . Ten items were significantly associated with higher park use $(\mathrm{p}<0.2)$ and were further assessed in the logistic regression models that adjusted for park size and number of participants living within 800 of the park (Table 3). Seven park features remained positively associated with high reported park use for physical activity $(p \leq 0.05)$. Most notably, the odds of a park being 'high use' rather than 'low use' was fourteen times higher if there were public access toilets (OR 13.93; $p=0.002$ ), nine times higher if $\mathrm{BBQs}$ were present (OR 9.24; $\mathrm{p}=0.003)$, six times higher if there was a skate park (OR 6.41; $\mathrm{p}=0.01)$, and lighting around courts and equipment (OR 6.09; $\mathrm{p}=0.012$ ), and nearly seven times higher if there were more than 25 trees present within the park (OR 6.72; $\mathrm{p}=0.010)$. High NDVI levels (i.e., park greenness) also appeared to be associated with higher park use, however this did not reach statistical significant $(\mathrm{p}=0.054)$. The number of activity spaces (i.e., sports courts or surfaces such as basketball courts) within the park was negatively associated with high park use $(\mathrm{p}=0.002)$ and this was dropped from subsequent analyses.

The adolescent attractiveness score was therefore based on these seven significant features: the presence of a skate park, walking paths, barbeques, picnic table, public access toilets, lighting around courts and equipment and number of trees $>25$.

\section{Confirming associations of park attractiveness scores and} frequency of reported park use for physical activity

The mean attractiveness score of parks reported to have been used for physical activity (3.2, SD 1.95) was significantly higher $(\mathrm{p}<0.001)$ than the non-reported parks (1.3, SD 1.17). When comparing parks by their level of reported use (or popularity), the mean attractiveness score of high use parks (4.3, SD 1.78) was significantly higher $(\mathrm{p}<0.001)$ than the low use parks (1.6, SD 1.36).

In logistic regression models that adjust for park size and number of participants living within $800 \mathrm{~m}$ of park, the odds of a park being in the high use category was 2.9 times higher $(\mathrm{p}<0.001)$ for every one-point increase in the adolescent park attractiveness score (i.e., for every additional feature present). In comparison, the odds of a park being in the high use category was only 1.1 times higher $(p=0.021)$ for every one-point increase in the adult attractiveness score. 
Table 3 The association of POSDAT item and reported 'high/low park use' by adolescents and odds ratios from logistic regression models assessing associations between park features (measured using POSDAT and GIS) and high/low park use after adjustment for park size and number of participants living within $800 \mathrm{~m}$ of park

\begin{tabular}{|c|c|c|c|c|c|}
\hline POSDAT item & $\begin{array}{l}\% \text { of low use parks }(n=43) \text { with } \\
\text { POSDAT item present or mean }(S D)\end{array}$ & $\begin{array}{l}\% \text { of high use parks }(n=15) \text { with } \\
\text { POSDAT item present or mean (SD) }\end{array}$ & $\begin{array}{l}\text { P-value (one-sided) } \\
\text { fishers exact or } t \text { - test }\end{array}$ & OR & $p$-value \\
\hline \multicolumn{6}{|l|}{ Activities } \\
\hline Activity space: Soccer & 7.0 & 0.0 & 0.422 & & \\
\hline Activity space: Football & 9.3 & 7.1 & 0.643 & & \\
\hline Activity space: Cricket & 11.6 & 0 & 0.230 & & \\
\hline Activity space: Baseball & 4.7 & 0 & 0.566 & & \\
\hline Activity space: Fitness circuit & 0 & 7.1 & 0.246 & & \\
\hline $\begin{array}{l}\text { Activity space: Basketball/ } \\
\text { netball hoops }\end{array}$ & 9.3 & 21.4 & 0.224 & & \\
\hline Activity space: Hockey & 2.3 & 0 & 0.754 & & \\
\hline Activity space: Athletics & 2.3 & 0 & 0.754 & & \\
\hline Activity space: Rugby & 2.3 & 0 & 0.754 & & \\
\hline $\begin{array}{l}\text { Activity space: Skateboarding/ } \\
\text { BMX }\end{array}$ & 4.7 & 28.6 & 0.027 & 6.41 & 0.011 \\
\hline Children's playground & 67.4 & 85.7 & 0.164 & 4.35 & 0.125 \\
\hline \multicolumn{6}{|l|}{ Environmental quality } \\
\hline Park on river or foreshore & 14.0 & 21.4 & 0.386 & & \\
\hline Water feature: Fountain & 4.7 & 0 & 0.566 & & \\
\hline Water feature: Any & 4.7 & 0 & 0.509 & & \\
\hline Other features: Waterbirds & 16.3 & 14.3 & 0.614 & & \\
\hline Other features: Gardens & 20.9 & 21.4 & 0.627 & & \\
\hline No features & 65.1 & 64.3 & 0.598 & & \\
\hline Number of trees $>25$ & 95.3 & 85.7 & 0.004 & 6.72 & 0.010 \\
\hline Walking paths present & 37.2 & 71.4 & 0.027 & 4.64 & 0.021 \\
\hline Path shade (High) & 4.7 & 7.1 & 0.600 & & \\
\hline Playground shaded & 23.3 & 42.9 & 0.224 & & \\
\hline Grass reticulated & 81.4 & 92.9 & 0.288 & & \\
\hline High NDVI & 25.5 & 53.3 & 0.051 & 3.32 & 0.054 \\
\hline \multicolumn{6}{|l|}{ Dogs } \\
\hline Dogs allowed & 95.3 & 100 & 0.566 & & \\
\hline \multicolumn{6}{|l|}{ Amenities } \\
\hline Barbeques & 14.0 & 57.1 & 0.003 & 9.24 & 0.003 \\
\hline Seating & 34.9 & 50.0 & 0.243 & & \\
\hline Picnic tables & 37.2 & 71.4 & 0.025 & 5.64 & 0.018 \\
\hline Public access toilets & 18.6 & 64.3 & 0.002 & 13.93 & 0.002 \\
\hline Public art present & 7.0 & 7.1 & 0.688 & & \\
\hline $\begin{array}{l}\text { Lighting: Around courts, } \\
\text { buildings, equipment }\end{array}$ & 16.3 & 50.0 & 0.017 & 6.09 & 0.012 \\
\hline \multicolumn{6}{|l|}{ Safety } \\
\hline $\begin{array}{l}\text { Park surrounded by minor } \\
\text { roads only }\end{array}$ & 72.1 & 78.6 & 0.461 & & \\
\hline Perimeter orientation ratio* & $30.94(25.00)$ & $32.49(21.26)$ & 0.831 & & \\
\hline Number of lots around park* & $10.63(7.00)$ & $12.00(8.36)$ & 0.537 & & \\
\hline Number of lots facing park* & $7.05(5.94)$ & $8.40(5.34)$ & 0.440 & & \\
\hline
\end{tabular}


Table 3 The association of POSDAT item and reported 'high/low park use' by adolescents and odds ratios from logistic regression models assessing associations between park features (measured using POSDAT and GIS) and high/low park use after adjustment for park size and number of participants living within $800 \mathbf{~ m}$ of park (Continued)

\begin{tabular}{llll}
\hline $\begin{array}{l}\text { Number of lots orientation } \\
\text { ratio* }\end{array}$ & $0.56(0.39)$ & $0.59(0.32)$ & 0.791 \\
Additional items & & & \\
Park size m2* & $14786.76(26944.14)$ & $21199.41(20378.49)$ & 0.585 \\
Distance to beach $(\mathrm{m})^{*}$ & $1426.65(2798.61)$ & $1370.81(1282.16)$ & 0.872 \\
Tree canopy area* & $1647.12(3461.58)$ & $3083.54(4462.38)$ & 0.215 \\
Tree canopy coverage & $10.80(7.75)$ & $14.12(13.98)$ & 0.266 \\
(\% total park) & & & 0.039 \\
NDVI * & $0.23(0.09)$ & $0.29(0.08)$ & 0.005 \\
Attractiveness score (Adult) * & $32.8(14.56)$ & $45.7(13.2)$ & 0.153 \\
Activity space count* & $0.48(1.05)$ & $0.46(74)$ & 0.002 \\
\hline
\end{tabular}

*Continuous independent variable.

Bold OR and $\mathrm{p}$ values $=$ the seven park features included in the adolescent attractiveness score for park use.

Factors that are predictive of use of closest park

A total of $27 \%$ of the 751 participants who reported using a park for physical activity reported using their closet park. Univariate analyses found no associations between age, sex, aboriginality and use of the closest park. Additionally, we found no associations between a park being in a higher socioeconomic area and park attractiveness or having more amenities. However, participants in the higher socioeconomic group were 1.5 times more likely to use their closest park. People who agreed with the statement "There are no parks/ovals close to where I live" were $55 \%$ less likely to use their closest park (OR 0.45; 95\%CI: 0.23-0.85, $\mathrm{p}=0.01$ ). Additionally, the adolescent park attractiveness score was associated with use of the closest park. For every attractiveness point increase in the closest park, the odds of using that park increased by $75 \%$ (CI 95\% 1.59-1.92, p < 0.001).

\section{Discussion}

There is a dearth of research on specific park features associated with park use for physical activity among adolescents. We found that high park use for physical activity by adolescents was associated with the presence of seven park features: lighting around courts and amenities, a skate park, walking paths, BBQs, picnic tables, public access toilets and a high number of trees. Moreover, odds of using a park with these features was 2.9 times higher for every one-point increase in the adolescent park attractiveness score (i.e., for every additional feature present).

This appears to be the first study to develop an adolescent-specific attractiveness score for parks. We also compared the use of a seven feature adolescent specific park-attractiveness score with our adult attractiveness score, which comprised of nine features. Attributes included in the adult attractiveness score that were not included in the adolescent score were: shade along paths; irrigated lawns; sporting facilities; birdlife; quiet surrounding roads; adjacent to ocean to river and the presence of a water feature. The presence of walking paths and lighting around courts and equipment were included in both scores. We found that while the adult attractiveness score was significantly associated with increased odds of high park use $(\mathrm{OR}=1.06)$, the association was greater when the attractiveness score specific to adolescents was used.

Studies to date have mostly associated park features with physical activity outcomes and traditionally these studies assume that park users frequent their closest park or a park within a specific researcher defined buffer $[2,10,11,31-34,37,38]$. This current study is unique for its target group because it examined features of parks that participants reported as being used for physical activity. Whilst some studies of adolescents have found the presence of courts to be associated with higher levels of physical activity, $[5,19]$, we found a negative association between the number of activity spaces present and park use for physical activity. Indeed, Byrne and Wolch (2009), suggest that while park attributes may shape use, the extent to which they impact potential user groups is largely unknown [39]. It is possible that in this rural centre, parks or playing fields that provide for a larger number of formal sporting spaces, have less appeal for adolescents who frequent the park for informal activities.

Certain park features of the attractiveness score (such as lighting around courts, buildings and equipment, the presence of a skatepark and walking paths that provide space for roller-skating, skateboarding, bicycling, walking and running) provide physical activity opportunities. Conversely, other features (such as barbeques, picnic tables and a high number of trees) may potentially reduce 
physical activity by encouraging sedentary behaviour. Yet, our study results indicate if these features are present, the park is more likely to be used by adolescents for physical activity. This may be in part, because adolescents who visit a park for physical activity may also require social amenities (such as toilets, picnic tables for seating and trees for shade) to remain in the park for longer periods of time, thus providing opportunity for prolonged participation in physical activity. Moreover, the presence of these amenities may encourage greater use by the community for a wide range of activities: greater use may attract other park users [23].

The use of GIS and remote sensing techniques enabled new park features to be objectively measured, further expanding the items previously collected with POSDAT. For example, the number of participants living within an $800 \mathrm{~m}$ buffer of the park, tree canopy coverage and the proportion of the park perimeter that had residential dwellings facing the park were all objectively measured using GIS rather than relying on auditing. Notably, a 'higher number of trees' in the park was significantly associated higher park use for physical activity. Whilst the other new items were not significantly associated with high park use in this study, future studies may also wish to include these measures, as associations may be found in studies with a larger sample size, more varied environments and/or with a different target groups (e.g. older adults who may only use public open space nearer to their home).

The greenness of a park may be an important feature that influences an adolescent's choice of parks. Whilst the calculation of NDVI did not achieve the conventional levels of significance in this study $(p=0.054)$, this may be due to the small sample size of parks or the lack of variation in the sample. It could also be due to the measurement limitation of using NDVI for small parks. For example, no standard deviation of NDVI could be determined because the pixel size required for NDVI calculation $(30 \mathrm{~m} \times 30 \mathrm{~m})$ was larger than some of the parks. Other studies however have found greenness is important therefore future studies may wish to include NDVI in studies of public open space and adolescents.

Examining features of parks actually used for physical activity, as opposed to the park closest to home, is recommended for studies examining the relationship between parks and physical activity. Notably, we found that less than a third of participants used the park closest to where they lived. Indeed, the perception "there are no parks close to where I live" was negatively associated with use of the closest park whereas park attractiveness was positively associated with use of the closest park. Those living in higher SES areas also were more likely to use their closest park. However, we found no association between parks in higher socioeconomic areas and park attractiveness, or having a higher amenity count. This is in contrast to the findings of Crawford and colleagues in Melbourne, Australia who found parks in higher socioeconomic areas are more likely to be more attractive and have more amenities [28].

This study is limited by the small number of parks included in the sample however this was unavoidable, given our study was set in a in a rural location. Furthermore, as a result of being a rural setting some POSDAT items could not be examined because they were not present in any of the parks in the study areas. Future studies undertaken in larger rural centres, should consider using all of the POSTDAT items, rather than those items used in this study. Some caution should be exercised when using orthoimagery to audit parks because the time of the year the imagery is captured may not reflect park conditions all year round. Another limitation of our study is that park use varies by season and associations found in this study were not stratified by season.

This focus of this study was on assessing park access, reported as being used from participants' residential locations. Further research may take into account the distance from participants' school or the park's location in terms of being along routes between home and school locations. Moreover, this study examined environmental characteristics of parks however, as suggested by Byrne and Wolch (2009), cultural preferences of potential park users should also be considered [39]. Finally, although this study found associations between objective park measures and levels of use, it is recommended that future studies also consider using both objective and subjective measures of park quality to better understand what influences park use among adolescents.

\section{Conclusions}

Park use for physical activity by adolescents was associated with seven features: presence of a skate park, walking paths, barbeques, picnic table, public access toilets, lighting around courts and equipment and number of trees $>25$. These features were combined to create an overall adolescent-attractiveness score, where for every additional feature present, parks were almost three times more likely to be used by adolescents. Further our adolescent attractiveness score was a better predictor of park use for physical activity than a previously developed adult-specific park attractiveness score. Given such a large number of adolescents do not meet recommended guidelines for physical activity, landscape architects might consider designing parks with such features to encourage increased adolescent physical activity through park usage.

Abbreviations

GIS: Geographic Information System; POSDAT: Public Open Space Desktop Auditing Tool; NDVI: Normalised Difference Vegetation Index. 


\section{Competing interests}

The authors declare that they have no competing interests.

\section{Authors' contributions}

$\mathrm{NE}$ conducted the analyses, interpreted the data and drafted the manuscript. MK, PH and BGC advised on data analysis and interpretation of results. All authors contributed to the study conception and design, provided input into to manuscript drafts and approved the final manuscript.

\section{Acknowledgements}

The Up4it Project was a Healthway funded initiative run in partnership with the Heart Foundation, Midwest Murchison Population Health and the Combined Universities Centre for Rural Health. Combined Universities Centre for Rural Health is a University Department of Rural Health funded by the Commonwealth Department of Health and Ageing and administered by the University of Western Australia. PH is supported on the RESIDE-II project by grants from the Western Australian Health Promotion Foundation (Healthway) (\#18921), and the NHMRC (Population Health Capacity Building Grant \#458668); BGC is supported by a NHMRC Principal Research Fellowship (\#1004900); SF is supported by Healthway Health Promotion Research Fellowships (\#21363). The input of Ms Bridget Beesley and Ms Sharyn Hickey for their work on the park spatial layer is gratefully acknowledged.

\section{Author details}

${ }^{1}$ Centre for the Built Environment and Health, School of Sport Science, Exercise and Health and School of Earth and Environment, University of Western Australia, 55 Broadway, Nedlands 6009, WA, Australia. ${ }^{2}$ Melbourne School of Population and Global Health, The University of Melbourne, Level 5, 207 Bouverie Street, Victoria 3010, Australia. 3School of Population Health, University of Western Australia, 55 Broadway, Nedlands 6009, Perth, Western Australia.

Received: 28 May 2014 Accepted: 30 January 2015

Published online: 18 February 2015

\section{References}

1. Hallal PC, Andersen LB, Bull FC, Guthold R, Haskell W, Ekelund U. Global physical activity levels: surveillance progress, pitfalls, and prospects. Lancet. 2012;380:247-57.

2. Roemmich JN, Epstein LH, Raja S, Yin L, Robinson J, Winiewicz D. Association of access to parks and recreational facilities with the physical activity of young children. Prev Med. 2006;43:437-41.

3. Jago R, Baranowski T, Harris M. Relationships between GIS environmental features and adolescent male physical activity: GIS coding differences. J Phys Act Health. 2006;3:230-42.

4. Dowda M, McKenzie TL, Cohen DA, Scott MM, Evenson KR, Bedimo-Rung $\mathrm{AL}$, et al. Commercial venues as supports for physical activity in adolescent girls. Prev Med. 2007:45:163-8.

5. Cohen D, Ashwood J, Scott M, Overton A, Evenson K, Staten L, et al. Public parks and physical activity among adolescent girls. Pediatrics. 2006;118:E1381-9.

6. $\quad$ Ding D, Sallis JF, Kerr J, Lee S, Rosenberg DE. Neighborhood environment and physical activity among youth: a review. Am J Prev Med. 2011;41:442-55.

7. Babey SH, Hastert TA, Yu H, Brown ER. Physical activity among adolescents: when do parks matter? Am J Prev Med. 2008;34:345-8.

8. Edwards N, Giles-Corti B, Larson A, Beesley B. The effect of proximity on park and beach use and physical activity among rural adolescents. J Phys Act Health. 2014;11(5):977-84.

9. Spengler JO, Floyd MF, Maddock JE, Gobster PH, Suau LJ, Norman GJ. Correlates of park-based physical activity among children in diverse communities: results from an observational study in two cities. Am J Health Promot. 2011;25:e1-9.

10. Potwarka LR, Kaczynski AT, Flack AL. Places to play: association of park space and facilities with healthy weight status among children. J Community Health. 2008;33:344-50

11. Wolch J, Jerrett M, Reynolds K, McConnell R, Chang R, Dahmann N, et al. Childhood obesity and proximity to urban parks and recreational resources: a longitudinal cohort study. Health Place. 2011;17:207-14.

12. Babey S, Brown ER, Hastert T. Access to Safe parks helps increase physical activity among teenagers. In: Book access to safe parks helps increase physical activity among teenagers. City: UCLA Centre for Health Policy Research; 2005.

13. Cohen DA, McKenzie TL, Sehgal A, Williamson S, Golinelli D, Lurie N. Contribution of public parks to physical activity. Am J Public Health. 2007;97:509-14.

14. Epstein LH, Raja S, Gold S, Paluch RA, Pak Y, Roemmich JN. Reducing sedentary behavior: the relationship between park area and the physical activity of youth. Psychol Sci. 2006;17:654-9.

15. Baran PK, Smith WR, Moore RC, Floyd MF, Bocarro JN, Cosco NG, et al. Park use among youth and adults: examination of individual, social, and urban form factors. Environ Behav. 2014;46:768.

16. Ries AV, Voorhees CC, Roche KM, Gittelsohn J, Yan AF, Astone NM. A quantitative examination of park characteristics related to park Use and physical activity among urban youth. J Adolesc Health. 2009;45:S64-70.

17. Timperio A, Giles-Corti B, Crawford DA, Andrianopoulos N, Ball K, Salmon J, et al. Features of public open spaces and physical activity among children: findings from the CLAN study. Prev Med. 2008;47:514-8.

18. Reed JA, Hooker SP. Where are youth physically active? A descriptive examination of 45 parks in a southeastern community. Childhood Obesity. 2012:8:124-31.

19. Floyd MF, Bocarro JN, Smith WR, Baran PK, Moore RC, Cosco NG, et al. Park-based physical activity among children and adolescents. Am J Prev Med. 2011;41:258-65.

20. Bell J, Wilson J, Liu G. Neighborhood Greenness and 2-year changes in body mass index of children and youth. Am J Prev Med. 2008;35(6):547-53.

21. Almanza E, Jerrett $M$, Dunton $G$, Seto $E$, Ann Pentz M. A study of community design, greenness, and physical activity in children using satellite, GPS and accelerometer data. Health Place. 2012;18:46-54.

22. Kaczynski AT, Henderson KA. Environmental correlates of physical activity: a review of evidence about parks and recreation. Leis Sci. 2007;29:315-54.

23. Giles-Corti B, Broomhall M, Knuiman M, Collins C, Douglas K, Ng K, et al. Increasing walking: how important is distance to, attractiveness, and size of public open space? Am J Prev Med. 2005;28:169-76.

24. Sugiyama T, Francis J, Middleton NJ, Owen N, Giles-Corti B. Associations between recreational walking and attractiveness, size, and proximity of neighborhood open spaces. Am J Public Health. 2010;100:1752-7.

25. Saelens BE, Frank LD, Auffrey C, Whitaker RC, Burdette HL, Colabianchi N. Measuring physical environments of parks and playgrounds: EAPRS instrument development and inter-rater reliability. J Phys Act Health. 2006;2006:S190-207.

26. Broomhall M, Giles-Corti B, Lange A. Quality of Public Open Space Tool (POST). In: Book Quality of Public Open Space Tool (POST). Australia: The University of Western Australia; 2004.

27. Kaczynski AT, Wilhelm Stanis SA, Besenyi GM. Development and testing of a community stakeholder park audit tool. Am J Prev Med. 2012;42:242-9.

28. Crawford D, Timperio A, Giles-Corti B, Ball K, Hume C, Andrianopoulos N, et al. Do features of public open spaces vary according to neighbourhood socio-economic status? Health Place. 2008;14:889-93.

29. Taylor BT, Fernando P, Bauman AE, Williamson A, Craig JC, Redman S. Measuring the quality of public open space using Google Earth. Am J Prev Med. 2011;40:105-12.

30. Edwards N, Hooper P, Trapp GSA, Bull F, Boruff B, Giles-Corti B. Development of a Public Open Space Desktop Auditing Tool (POSDAT): a remote sensing approach. Appl Geogr. 2013;38:22-30.

31. Rundle A, Quinn J, Lovasi G, Bader MDM, Yousefzadeh P, Weiss C, et al. Associations between body mass index and park proximity, size, cleanliness, and recreational facilities. Am J Health Promot. 2013;27:262-9.

32. Tucker P, Irwin JD, Gilliland J, He M, Larsen K, Hess P. Environmental influences on physical activity levels in youth. Health Place. 2009;15:357-63.

33. Barton $\mathrm{H}$, Grant M. A health map for the local human habitat. J R Soc Promot Heal. 2006;126:252-3.

34. Kaczynski AT, Potwarka LR, Smale BJA, Havitz ME. Association of parkland proximity with neighborhood and park-based physical activity: variations by gender and Age. Leis Sci. 2009;31:174-91.

35. Australian Bureau of Statistics. Socio-Economic Indexes for Areas (SEIFA), Australia. In Book Socio-Economic Indexes for Areas (SEIFA), Australia (Editor ed.^eds.). City; 2006.

36. Hooper P, Giles-Corti B, Knuiman M. Evaluating the implementation and active living impacts of a state government planning policy designed to create walkable neighborhoods in Perth, Western Australia. Am J Health Promot. 2013;28:S5-18. 
37. Frank LD, Saelens BE, Chapman J, Sallis JF, Kerr J, Glanz K, et al. Objective assessment of obesogenic environments in youth: geographic information system methods and spatial findings from the neighborhood impact on kids study. Am J Prev Med. 2012;42:e47-55.

38. Boone-Heinonen J, Popkin BM, Song Y, Gordon-Larsen P. What neighborhood area captures built environment features related to adolescent physical activity? Health Place. 2010;16:1280-6.

39. Byrne J, Wolch J. Nature, race, and parks: past research and future directions for geographic research. Prog Hum Geogr. 2009;33(6):743-65.

Submit your next manuscript to BioMed Central and take full advantage of:

- Convenient online submission

- Thorough peer review

- No space constraints or color figure charges

- Immediate publication on acceptance

- Inclusion in PubMed, CAS, Scopus and Google Scholar

- Research which is freely available for redistribution 